\title{
A produção da subjetividade e as relações de poder na escola: uma reflexão sobre a sociedade disciplinar na configuração social da atualidade*
}

\author{
Maria Regina dos Santos Prata
}

U niversidade Estácio de Sá, M estrado em Educação

\section{Introdução}

Este artigo visa articular a produção da subjetividade contemporânea com as relações de poder que circulam na escola, não somente na relação professoraluno, mas sobretudo discutindo o lugar que a instituição escolar ocupa na configuração social da atualidade. Trata-se de uma reflexão teórica que busca discutir a inserção da escola no contexto atual.

Quando falamos de uma produção da subjetividade, estamos deixando de lado qualquer noção de subjetividade pré-social, pois a subjetividade é um constante processo social de geração (Hardt \& Negri, 2001). Assim, falar em produção da subjetividade significa dizer que esta última não é entendida como origem, mas como um processo, de acordo com a configuração sócio-histórica em que se situa. Nesse sentido, podemos dizer que a subjetividade não é um

* Trabalho apresentado no GT Psicologia da Educação, durante a $26^{\mathrm{a}}$ Reunião Anual da ANPEd, realizada de 5 a 8 de outubro de 2003, em Poços de Caldas (MG). dado prévio nem um ponto de partida, mas um ponto de chegada de um processo complexo, tal como um devir (Birman, 2000).

A idéia de produção da subjetividade pode ser enriquecida pela noção de subjetivação (Foucault, 1988, 1990; Deleuze, 1992). Essa noção vem sempre precedida das palavras "formas", "modos", "processos", que apontam que a subjetivação nunca está acabada, mas se constitui como um processo contínuo (Prata, 2001). A partir dessa perspectiva, há múltiplas maneiras diferentes de se subjetivar no decorrer da história, em que o sujeito pode fixar, manter ou transformar sua identidade (Foucault, 1997).

Dito em outras palavras, a suposição é que a subjetividade hoje se produz diferentemente do que se produziu, por exemplo, no início do século XX. De modo não casual, a instituição escolar fez e faz parte dessa produção, uma vez que, se por um lado ela é um lugar fundamental na constituição da subjetividade, por outro ela também está inserida num amplo contexto. Nesse sentido, a engrenagem da escola é atravessada e marcada pela configuração social, mas também tem o papel de definir o sujeito, seja por meio 
das relações de poder entre professores e alunos, seja na forma pela qual concebe a aprendizagem e transmite o saber.

Para discutir a forma pela qual as relações de poder circulam no espaço escolar e a produção da subjetividade por elas, aproveitaremos a concepção de sociedade disciplinar (Foucault, 1977) para, num segundo momento, problematizarmos esse modelo na atualidade. Pois, ainda que alguns rastros das técnicas disciplinares permaneçam em nossos dias, a questão que se apresenta para nós é: quando voltamos nosso olhar para as instituições contemporâneas, em particular para a escola, será que o diagnóstico de Foucault ainda compreende completamente a forma pela qual as relações de poder se estabelecem nessa instituição? Não valeria a pena refletirmos sobre o poder disciplinar em função da crise das instituições e das mudanças das relações de poder da atualidade? Como a subjetividade está sendo produzida no deslocamento da sociedade disciplinar para os dias de hoje?

Antes de encaminharmos a problemática, é importante apresentarmos uma precaução, sublinhada por Foucault, sobre a análise do poder: o poder deve ser analisado como algo que funciona em cadeia, não está localizado aqui ou ali, nem está nas mãos de alguns. O poder não é um bem, mas é algo que se exerce em rede, e nessa rede todos os indivíduos circulam, sendo que qualquer um pode estar em posição de ser submetido ao poder, mas também de exercêlo. Nessa perspectiva, não se trata da questão de "quem tem o poder", mas de estudá-lo no ponto em que se implanta e produz seus efeitos reais. É nesse contexto que o autor parece se interessar pelos efeitos de verdade produzidos pelo poder, como esse último se legitima nas relações criando discursos que funcionam como norma (Foucault, 1999a).

\section{As relações de poder no panoptismo}

Segundo Foucault (1977), as relações de poder estabelecidas no século XX nas instituições, seja na família, na escola, nas prisões ou nos quartéis, foram marcadas pela disciplina, cujo objetivo principal era a produção de corpos dóceis, eficazes economicamente e submissos politicamente (Vaz, 1999).

Para atingir esse objetivo, a partir do final do século XVIII as sociedades disciplinares começaram a distribuir os indivíduos no espaço por meio de técnicas de enclausuramento e/ou de organizações hierárquicas de lugares específicos. Todas as atividades eram controladas temporalmente, o que possibilitava, por exemplo, o isolamento do tempo de formação e do período da prática do indivíduo. Com isso, a aprendizagem poderia ser normatizada, e as forças produtivas seriam compostas a fim de obter um aparelho eficiente.

As disciplinas, organizando as "celas", os "lugares" e as "fileiras", criam espaços complexos: ao mesmo tempo arquiteturais, funcionais e hierárquicos. São espaços que realizam a fixação e permitem a circulação; recortam segmentos individuais e estabelecem ligações operatórias; marcam lugares e indicam valores; garantem a obediência dos indivíduos, mas também uma melhor economia do tempo e dos gestos [...]. A primeira das grandes operações da disciplina é então a constituição de "quadros vivos" que transformam as multidões confusas, inúteis ou perigosas em multiplicidades organizadas. (Foucault, 1977, p. 135, aspas do original).

Os quadros vivos eram ao mesmo tempo uma técnica de poder e um processo de saber, cuja intenção era a de dominar a diversidade, impondo-lhe uma ordem. As sociedades disciplinares substituíram as antigas sociedades de soberania, tendo seu início no século XVIII e atingindo seu ápice no século XX. ${ }^{1}$ No entanto, a partir do século XVII, já começou a aparecer uma nova mecânica do poder, com instrumentos novos e incompatíveis com as relações de

${ }^{1}$ A referência bibliográfica utilizada aqui é Em defesa da sociedade (Foucault, 1999a). Este livro apresenta uma versão completa das aulas publicadas em Microfísica do poder (Foucault, 1979) além de outras aulas não publicadas nesse último livro. 
soberania, que incidiu mais sobre os corpos do que sobre a terra e seus produtos. Foucault completa:

É um mecanismo de poder que permite extrair dos corpos tempo e trabalho, mais do que bens e riqueza. É um tipo de poder que se exerce continuamente por vigilância e não de forma descontínua por sistemas de tributos e de obrigações crônicas. (1999a, p. 42)

As sociedades disciplinares veiculam uma forma de poder ligado à ortopedia social, que tenta assegurar a ordenação das multiplicidades humanas. Trata-se de produzir corpos dóceis, tornando o exercício do poder economicamente menos custoso possível, estendendo os efeitos do poder social ao máximo de intensidade e tão longe quanto possível, e ainda ligando o crescimento econômico do poder ao rendimento dos aparelhos pelos quais se exerce, sejam pedagógicos, militares, industriais, médicos. Em suma, fazendo crescer tanto a docilidade quanto a utilidade de todos elementos do sistema (Foucault, 1977, p. 191).

As formas de poder exercidas na disciplina podem ser exemplificadas pelo modelo ortopédico do Panopticon, que foi definido inicialmente por Jeremy Bentham (Foucault, 1977; 1997; 1999b). O Panopticon era um edifício em forma de anel, com um pátio no meio do qual havia uma torre central, com um vigilante. Esse anel dividia-se em pequenas celas que davam tanto para o interior quanto para o exterior, permitindo que o olhar do vigilante as atravessasse. Essa forma arquitetônica das instituições valia para as escolas, hospitais, prisões, fábricas, hospícios (Foucault, 1977).

O Panopticon era um espaço fechado, recortado e vigiado em todos os seu pontos. Nele os indivíduos estavam inseridos num lugar fixo, com os menores movimentos e acontecimentos controlados. $\mathrm{O}$ poder era exercido segundo uma figura hierárquica contínua, no qual cada um podia ser constantemente localizado, examinado e distribuído (Foucault, 1977). Nessa perspectiva, a forma de poder exercida no panoptismo repousou, sobretudo no exame.
$\mathrm{O}$ exame combina as técnicas da hierarquia que vigia e as da sanção que normaliza. É um controle normalizante, uma vigilância que permite qualificar, classificar e punir. Estabelece sobre os indivíduos uma visibilidade através da qual eles são diferenciados e sancionados. É por isso que em todos os dispositivos de disciplina o exame é altamente ritualizado. Nele vêm-se reunir a cerimônia do poder e a forma da experiência, a demonstração da força e o estabelecimento da verdade. No coração dos processos de disciplina, ele manifesta a sujeição dos que são percebidos como objetos e a objetivação dos que se sujeitam. A superposição das relações de poder e das de saber assume no exame todo o seu brilho visível. (Foucault, 1977, p. 164-165)

Portanto, a vigilância hierárquica sobre os indivíduos permite a articulação de um poder com um saber, que se ordena em torno da norma, do que é ou não normal, do que é correto ou incorreto, do que se deve ou não se deve fazer (Foucault, 1999b, p. 88).

É a partir dessas relações do poder com o saber que Gore (2000) explica como os efeitos de verdade do poder podem ser produzidos nos discursos educacionais.

Mecanismos de poder-saber funcionam não apenas em relação a pedagogias defendidas em discursos educacionais, isto é, em relação a visões sociais e práticas instrucionais particulares, promulgadas em nome da pedagogia, mas também em relação à pedagogia dos argumentos, que caracterizam discursos educacionais específicos, isto é, aos próprios argumentos. (p. 14)

Um determinado discurso pode ser, ao mesmo tempo, instrumento e efeito de poder, mas também obstáculo, ponto de resistência ou ponto de partida de uma estratégia oposta: "O discurso veicula e produz poder; reforça-o, mas também o mina, expõe, debilita e permite barrá-lo... Não existe um discurso do poder de um lado e, em face dele, um outro, contraposto" (Foucault apud Gore, 2000, p. 15).

A partir da possibilidade da veiculação de normas nos discursos educacionais, vale aproveitar a exposição que Ariès (1981) faz do surgimento da vida 
escolástica e sua articulação com a disciplina. De acordo com o autor, a diferença essencial entre a escola da Idade Média e a dos tempos modernos residiu na introdução da disciplina, que era um meio de isolamento e adestramento das crianças.

Se a escola medieval não era destinada à educação da infância, sendo uma espécie de escola técnica que acolhia de forma indiferente crianças, jovens e adultos, na escola do século XIX os mestres começaram a submeter o aluno a um controle cada vez mais rígido e as famílias passaram a pensar numa educação "séria". Desse modo, a instituição ideal para as crianças passou a ser o internato (Ariès, 1981).

A disciplina não se traduzia simplesmente por melhor vigilância interna, mas impunha às famílias o respeito pelo ciclo escolar integral, que ao final do século XIX passou a durar no mínimo quatro ou cinco anos. Nesse movimento, uma nova noção de moral começou a distinguir a criança na escola, separando-a: a noção de criança bem educada. Esta seria preservada das rudezas e da imoralidade, que passaram a ser identificadas com traços específicos das camadas populares e dos moleques (Ariès, 1981).

Aproveitando as hipóteses de Foucault e Ariès, podemos dizer que a forma pela qual a instituição escolar se implantou no século XX se articulou às normas disciplinares, com uma concepção de valor do que seria ser "bem educado". Louro (1997) complementa:

Diferenças, distinções, desigualdades... A escola entende disso. Na verdade, a escola produz isso. Desde seus inícios, a instituição escolar exerceu uma ação distintiva. Ela se incumbiu de separar os sujeitos, tornando aqueles que nela entravam distintos dos outros, os que a ela tinham acesso. Ela dividiu também, internamente, os que lá estavam, através de múltiplos mecanismos de classificação, ordenamento, hierarquização [...]. (p. 57)

Sabemos que as características sinalizadas acima infelizmente ainda são fecundas nas instituições escolares de nossos dias. Porém, ainda que possamos reconhecer vestígios do poder disciplinar hoje, será que as relações de poder entre professores e alu- nos na escola ainda se exercem exclusivamente segundo o modelo da disciplina? O panoptismo sobrevive na atualidade?

\section{0 pós-panoptismo, a sociedade de controle e o Império}

Segundo Deleuze (1992), o modelo da sociedade disciplinar pode ser questionado, pois os meios de confinamento, tais como a prisão, o hospital, a fábrica, a escola e a família, encontram-se, na atualidade, numa crise generalizada. Para o autor, são as sociedades de controle que substituem a disciplina, pois nas sociedades disciplinares não se parava de recomeçar, enquanto nas sociedades de controle nunca se termina nada. Assim como a empresa vem substituir a fábrica, a formação permanente tende a substituir a escola, e o controle contínuo, o exame.

Nas sociedades disciplinares o indivíduo não parava de passar de um espaço fechado a outro, cada um com suas leis (primeiro a família, depois a escola, depois a fábrica etc.). Nelas encontramos dois pólos: a assinatura que indica o indivíduo e o número da matrícula que indica sua posição na massa. $\mathrm{O}$ poder aqui é ao mesmo tempo massificante e individuante, constituindo num corpo único aqueles sobre os quais se exerce e moldando a individualidade de cada membro do corpo (Deleuze, 1992).

Em contrapartida, na sociedade de controle o essencial tende a não ser mais uma assinatura ou um número, mas uma cifra, uma senha que marca o acesso à informação ou à rejeição. Os indivíduos tornamse divisíveis, e as massas tornam-se "amostras", "dados" ou "bancos", em que o controle é contínuo e a comunicação é instantânea (idem).

O campo da educação será um meio cada vez menos fechado, distinto do meio profissional, pois os dois tenderão a desaparecer em favor da formação permanente, de um controle contínuo que se exercerá sobre o "operário-aluno" ou o "executivo-universitário". Essa configuração social não é necessariamente melhor do que a anterior, mas traduz um novo regime de dominação. 
Não se deve perguntar qual é o regime mais duro, ou o mais tolerável, pois é em cada um deles que se enfrentam as liberações e as sujeições. Por exemplo, na crise do hospital como meio de confinamento, a setorização, os hospitais-dia, o atendimento a domicílio puderam marcar o início de novas liberdades, mas também passaram a integrar mecanismos de controle que rivalizavam com os mais duros confinamentos. Não cabe temer ou esperar, mas buscar novas armas. (Deleuze, 1992, p. 220)

Embora o diagnóstico de Deleuze ainda seja novo, ele é inspirador à discussão da crise das instituições e das relações de poder na escola. Como precaução, se acreditamos que estamos vivendo em outra configuração social, o exercício é não tomar esse deslocamento como necessariamente negativo, estabelecendo um juízo moral sobre ele. Assim, se "mudaram as técnicas de poder, mudou o sentido da vida que nossa cultura nos propõe, mudou o sujeito. Por estarmos no seu início, por ainda assistirmos à instalação de uma nova forma social, é difícil precisar seus contornos" (Vaz, 1999, p. 11). A partir dessa perspectiva, o exercício é não revocar, na crise das instituições, o poder disciplinar, mas entender que a crise desse último talvez possa deflagrar uma nova produção subjetiva e um outro modo de veiculação das relações de poder na instituição escolar.

De acordo com Bauman (2001), podemos questionar o modelo do Panóptico na contemporaneidade. Além de ser uma estratégia cara, uma vez que a manutenção dos internos no espaço vigiado compreendia uma gama de tarefas administrativas custosas e complicadas, o Panóptico criava uma tensão entre as tarefas dos administradores, pois eles deviam ao mesmo tempo manter sua própria mobilidade e rotinizar o fluxo do tempo dos vigiados: os "rotinizadores" ficavam presos ao lugar dentro do qual os vigiados estavam confinados.

Diferentemente do panoptismo, o poder hoje pode se mover com a velocidade do sinal eletrônico e tornou-se verdadeiramente extraterritorial, não mais limitado pela resistência do espaço.
Isso dá aos detentores do poder uma oportunidade verdadeiramente sem precedentes: eles podem se livrar dos aspectos irritantes e atrasados da técnica de poder do $\mathrm{Pa}$ nóptico. O que quer que a história da modernidade seja no estágio presente, ela é também, e talvez acima de tudo, pósPanóptica. O que importava no Panóptico era que os encarregados "estivessem lá", próximos, na torre de controle. O que importa nas relações de poder pós-panóptica é que as pessoas que operam as alavancas do poder de que depende o destino dos parceiros menos voláteis na relação podem fugir do alcance a qualquer momento - para a pura inacessibilidade. (Bauman, 2001, p. 18, grifos e aspas do original)

Como sugere Mathiensen (apud Bauman, 2001), deslocamos do modelo panóptico para um modelo do tipo sinóptico: agora são muitos os que observam poucos, os espetáculos tomam o lugar da supervisão e a obediência aos padrões tende a ser alcançada pela tentação e pela sedução, e não mais pela coerção, aparecendo sob o disfarce do livre-arbítrio, em vez de revelar-se como força externa.

Para Hardt e Negri (2001), na modernidade as instituições ocuparam um lugar diferente do que ocupam hoje. Aproveitando as hipóteses lançadas por Deleuze (1992), os autores falam que o indivíduo, ao longo da vida, passava linearmente pelas várias instituições e era por elas formado. Cada instituição tinha suas próprias regras e lógicas de subjetivação, protegendo o indivíduo, pelo menos parcialmente, contra a força das outras instituições. Os territórios eram bem definidos, havia uma clara distinção entre o interior e o exterior institucional e a função que cabia a cada instituição. No entanto, o lugar da produção da subjetividade na contemporaneidade não é mais definido desse modo, podendo-se dizer que as instituições disciplinares estão em crise:

A crise significa, em outras palavras, que hoje os cercados que costumavam definir o espaço limitado das instituições foram derrubados, de modo que a lógica que funcionava principalmente dentro das paredes institucionais agora se espalha por todo terreno social. Interior e exterior estão se tornando impossíveis de distinguir. (p. 216). 
Tal diluição dos cercados institucionais vem sinalizar uma mudança no modo pelo qual o poder marca seu espaço de circunscrição. Dessa maneira, Hardt e Negri (2001) colocam que hoje surge uma nova forma de supremacia operante, denominada pelos autores de império. $\mathrm{O}$ conceito de império caracteriza-se principalmente pela ausência de fronteiras e postula um regime que abrange a totalidade do espaço, ou que de fato governa todo o mundo "civilizado".

O império é um regime sem fronteiras temporais, não se limita a nenhuma região em especial, e seu poder de mando funciona em todos registros da ordem social. Em outras palavras, a produção de subjetividade na sociedade imperial tende a não se limitar a qualquer lugar exclusivo, nem a um território em particular, nem a alguma instituição específica. Essa característica corresponde a uma indeterminação da forma das subjetividades produzidas, sendo que uma característica importante do império é a tendência à neutralização das diversidades.

Acompanhando esse deslocamento da configuração social, outra subjetividade é produzida, ou melhor, produz-se outro modo de se subjetivar. Esse novo modo está presente também na escola e marca a forma pela qual as relações entre professores e alunos se exercem.

\section{A produção da subjetividade e a escola}

Como adiantamos na introdução, estamos supondo que a subjetividade é sempre produzida, ou seja, ela não está na origem nem é imanente à natureza humana. Mesmo se considerarmos determinados modos de a subjetividade se organizar em relação ao psíquico, esses modos estão relacionados aos padrões identitários e normativos que se constituem em cada época. ${ }^{2}$ Esses padrões identitários estão ativamente

${ }^{2}$ Em contrapartida, uma questão presente aqui é por que alguém ocupa uma determinada posição de sujeito, e não outra, em sua organização subjetiva. Esta questão se remete à problemática da singularidade psíquica, daquilo que diferencia um sujeito de presentes não só nas macrorrelações, mas também circulam nas microrrelações entre os sujeitos.

Ora, se não há uma subjetividade transcendental com valores universais válidos para qualquer tempo e lugar, se não há uma constituição psíquica que valha para qualquer época, uma vez que ela é sempre produzida em determinado tempo, as regras transmitidas nas relações entre professores e alunos na escola também se modificam. Mudam as regras, mudam as formas de sujeição, mudam as formas de transgressão, mudam os processos de subjetivação.

Talvez o que esteja sendo sinalizado na crise $d a$ autoridade docente (Aquino, 1996b; 1998), ainda que muitas vezes inconscientemente e de diferentes modos, é justamente a falência de um modelo de instituição calcado na idéia de disciplina. ${ }^{3}$ Podemos supor que é a própria configuração social que está se modificando, e essa modificação está ligada à produção de outro sujeito, que se presentificará também nas relações entre professores e alunos, causando, muitas vezes, um estranhamento em ambas as partes.

Mesmo se considerarmos que os professores fazem parte dessa nova produção subjetiva, podemos perguntar se algumas vezes seu discurso não se mantém amarrado em valores construídos na época em que eles próprios foram educados. Em outras palavras, o professor escolar muitas vezes insiste num diagnóstico da rebeldia do aluno a partir do modelo do poder disciplinar em que ele, professor, foi sujeitado. Porém, para os alunos, o professor pode aparecer como alguém desatualizado, seja em função das informações tecnológicas que eles rapidamente obtêm, ou mesmo em função da postura disciplinar creditada, em princípio, aos docentes. Talvez a forma mais apropriada de encaminharmos essa problemática seja tentando sair do discurso da "culpabilização

outro. No entanto, deixamos o aprofundamento desta problemática para outro momento, pois este não é o objetivo principal deste trabalho.

${ }^{3}$ Sobre a discussão de como o poder disciplinar pode gerar indisciplina, ver o ilustrativo artigo de Guirado (1996). 
generalizada", entendendo que tanto os professores quanto os alunos afetam e são afetados pelo mesmo processo de mudança social.

Mais do que um desencontro entre gerações distintas, o que se apresenta aqui é um processo de transformação social que abarca a instituição escolar e seus agentes. Dessa maneira, conforme coloca Aquino (1996a), a indisciplina pode estar indicando o impacto do ingresso de um novo sujeito histórico, com outras demandas e valores, numa ordem arcaica e despreparada para absorvê-lo.

Nesse sentido, a gênese da indisciplina não residiria na figura do aluno, mas na rejeição operada por esta escola incapaz de administrar as novas formas de existência social concreta, personificada nas transformações do perfil da clientela.

Indisciplina, então, seria sintoma de injunção da escola idealizada e gerida para um determinado tipo de sujeito e sendo ocupada por outro. Equivaleria, pois, a um quadro difuso de instabilidade gerado pela confrontação deste novo sujeito histórico a velhas formas institucionais cristalizadas. Ou seja, denotaria a tentativa de rupturas, pequenas fendas em um edifício secular como é a escola, potencializando assim uma transição institucional, mais cedo ou mais tarde, de um modelo autoritário de conceber e efetivar a tarefa educacional para um modelo menos elitista e conservador. (Aquino, 1996a, p. 45)

O mal-estar na confrontação dos alunos e professores fala do modo pelo qual os próprios agentes institucionais são atravessados pela configuração social, mas também coloca em jogo as transformações sociais que esses agentes possibilitam. Tal como peças do tabuleiro social, as instituições desenham novas configurações, o que implica uma análise transversal ao âmbito didático-pedagógico (Aquino, 1996a).

Abstenhamo-nos, pois, de supor a escola como donatária imediata de um social abstrato, encarado como um terceiro em relação às instituições. Ele, o decantado social, também é efeito, e nunca causa primeira. (Idem, p. 41)
Portanto, para além da impotência que alguns professores sentem em relação à indisciplina do aluno, talvez essa última possa estar deflagrando a existência de outros sujeitos em sala de aula, marcados por essa nova modalidade de organização da instituição escolar, mas que também a constituem. Nessa medida, podemos dizer que, se por um lado a escola reproduz os valores hegemônicos da sociedade, por outro, pelos impasses enfrentados em sala de aula, ela também participa da transformação desses valores, pois é um lugar fundamental na produção de sujeitos, sejam professores ou alunos.

MARIA REGINA DOS SANTOS PRATA, doutora em saúde coletiva pelo Instituto de Medicina Social da Universidade do Estado do Rio de Janeiro, é professora do mestrado em educação da Universidade Estácio de Sá e membro do Espaço Brasileiro de Estudos Psicanalíticos. Últimas publicações: Da norma disciplinar à iniciativa: os processos subjetivos e parâmetros normativos contemporâneos. In: Peixoto Júnior, Carlos Augusto (org.) Formas de subjetivação (Rio de Janeiro: Contra Capa, 2004); Transgressão e violência na atualidade. In: Plastino, Carlos Alberto (org.) Transgressões (Rio de Janeiro: Contra Capa, 2002); Foucault e os modos de subjetivação. Cadernos do Espaço Brasileiro de Estudos Psicanalíticos, v. 1, nº 1, Rio de Janeiro, 2001. Pesquisa em desenvolvimento: A produção da subjetividade e as novas relações de poder na configuração escolar da atualidade. E-mail: mrprata@uol.com.br

\section{Referências bibliográficas}

AQUINO, Júlio Groppa, (1996a). A desordem na relação professoraluno: indisciplina, moralidade e conhecimento. In: AQUINO, J. G. (org.). Indisciplina na escola: alternativas teóricas e práticas. São Paulo: Summus.

(1996b). Confrontos em sala de aula. São Paulo: Summus.

, (1998). A violência escolar e a crise da autoridade docente. Cadernos Cedes, n $^{\circ}$ 47, p. 7-19.

ARIÈS, Philipe, (1981). História social da criança e da família. Rio de Janeiro: Afiliada.

BAUMAN, Zygmund, (2001). Modernidade líquida. Rio de Janeiro: Jorge Zahar Editor. 
A produção da subjetividade e as relações de poder na escola

BIRMAN, Joel, (2000). Entre cuidado e saber de si: sobre Foucault e a psicanálise. Rio de Janeiro: Relume Dumará.

DELEUZE, Gilles, (1992). Conversações. Rio de Janeiro: Editora 34.

FOUCAULT, Michel, (1977). Vigiar e punir. Petrópolis: Vozes. , (1988). Dits et écrits - III. Paris: Gallimard.

(1990). História da sexualidade 2 - o uso dos prazeres. Rio de Janeiro: Graal.

, (1997). A sociedade punitiva. In: Resu-

mo dos cursos do Collège de France. Rio de Janeiro: Jorge Zahar, p. 25-44.

, (1999a). Em defesa da sociedade. São Paulo: Martins Fontes.

(1999b). A verdade e as formas jurídicas. Rio de Janeiro: Nau.

GORE, Jennifer, (2000). Foucault e educação: fascinantes desafios. In: SILVA, T. T. (org.) O sujeito da educação; estudos foucaultianos. Petrópolis: Vozes, p. 9-20.

GUIRADO, Marlene (1996). Poder indisciplina: os surpreendentes rumos das relações de poder. In: AQUINO, J. G. (org.)
Indisciplina na escola: alternativas teóricas e práticas. São Paulo: Summus, p. 57-72

HARDT, Michael, NEGRI, Antonio, (2001). Império. São Paulo: Record.

LOURO, Guacira, (1997). A construção escolar das diferenças. In: LOURO, G. (org.) Gênero, sexualidade e educação. Petrópolis: Vozes, p. 57-87.

PRATA, Maria Regina, (2001). Foucault e os modos de subjetivação. Cadernos do Espaço Brasileiro de Estudos Psicanalíti$\cos$, v. $1, \mathrm{n}^{\mathrm{o}} 1$, p. 37-40.

, (2003). A produção da subjetividade e as relações de poder na escola. Disponível em: <www.anped.org.br/ inicio.htm>. Acesso em 10 ago. 2003

VAZ, Paulo, (1999). Corpo e risco. Fórum Media, Viseu, v. 1, nº 1, p. 101-111. Disponível em: <www.eco.ufrj.br/ciberidea/artigos/corpo/pdf/corpoerisco.pdf>. Acesso em set. 2003.

Recebido em março de 2004 Aprovado em junho de 2004 


\title{
Resumos/Abstracts
}

\author{
Maria Regina dos Santos Prata \\ A produção da subjetividade e as relações de poder na escola: uma reflexão sobre a sociedade disciplinar na configuração \\ social da atualidade \\ Pretende articular a produção da subjetividade contemporânea com as relações de poder que circulam na escola, discutindo o lugar \\ que essa instituição ocupa na configuração social da atualidade. A partir da concepção de sociedade disciplinar de Michel Foucault \\ (1977), busca problematizar a validade e os limites desse modelo na contemporaneidade. Trata-se de reflexão teórica que visa \\ inserir a instituição escolar no contexto sócio-histórico, não só tematizando seu lugar como reprodutora dos padrões hegemônicos \\ da sociedade, mas também sublinhando sua importância na produção da subjetividade e na revisão dos valores construídos social- \\ mente.
}

Palavras-chave: produção da subjetividade; relações de poder; escola

The production of subjectivity and relations of power in the school: a reflection on the disciplinary society in the social configuration of the present time

The text seeks to articulate the production of contemporary subjectivity with the relations of power that circulate in the school, discussing the place this institution occupies in the social configuration of the present time. Based on Michel Foucault's conception of the disciplinary society (1977), the essay seeks to examine the validity and the limits of this model for contemporary society. It constitutes a theoretical reflection which aims at inserting the school as institution in the socio-historical context, not only thematising its place as a reproducer of hegemonic social standards, but also stressing its importance for the production of subjectivity and for the revision of socially constructed values.

Key-words: production of subjectivity; relations of power; school 